\title{
Química para os mais novos
}

\section{Marta C. Corvo}

Departamento de Química

Faculdade de Ciências e Tecnologia

Universidade Nova de Lisboa

marta.corvo@fct.unl.pt
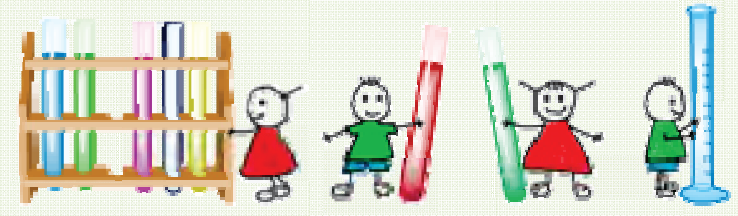

\section{Introdução}

A actividade desta edição propõe experiências com substâncias líquidas para melhor entender uma propriedade bastante comum, a viscosidade. Utilizando líquidos comuns do nosso quotidiano testaremos a viscosidade tentando perceber como esta pode variar. Desta feita, o trabalho em equipa será essencial para a execução experimental - o ideal será quatro ou mesmo seis mãos!

\section{A corrida dos berlindes}

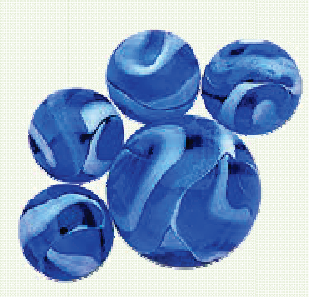

Material:

- 4 Copos de plástico, direitos e transparentes

- 4 Berlindes de igual tamanho

- 3 Berlindes de tamanhos diferentes (de preferência do mesmo tipo de material)

- Marcador

- Régua

- Cronómetro

- Água $(350 \mathrm{~mL})$

- Mel $(350 \mathrm{~mL})$

- Gel de banho (1L)

- Óleo alimentar (350 mL)

- 4 Colheres compridas

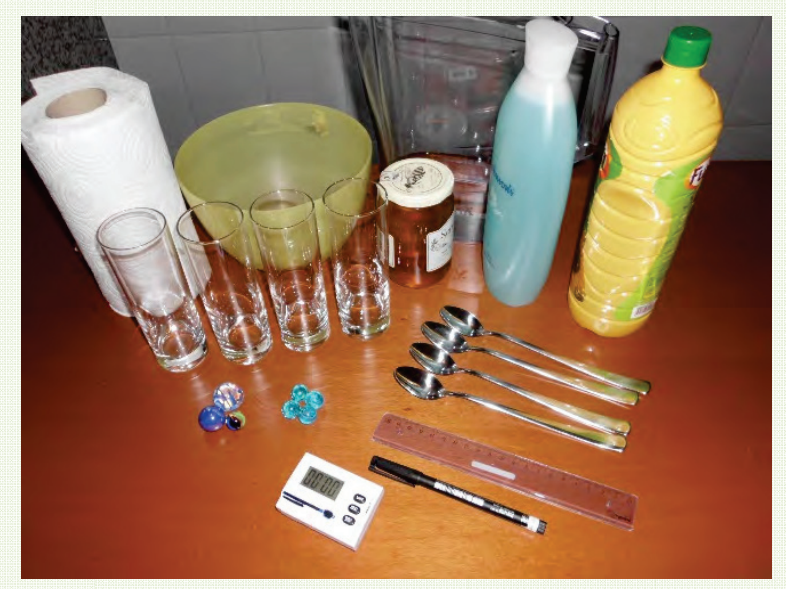

- Papel absorvente 


\section{Procedimento:}

1. Com o auxílio da régua e do marcador, marcar uma distância de $2 \mathrm{~cm}$ do topo de cada copo.

2. Identificar os copos com água, gel de banho, óleo e mel.

3. Colocar cada um dos líquidos no copo respectivo, enchendo até à marca.

4. Consoante as idades, esta experiência poderá ser feita de um modo mais qualitativo, ou quantitativo. Dos passos 5 a 7 exemplifica-se a opção qualitativa.

5. Com os quatro berlindes iguais, segurar cada berlinde imediatamente acima e no centro de cada um dos copos. Precisaremos de quatro mãos!

6. Largar os berlindes ao mesmo tempo e verificar qual a ordem de chegada. Registar as observações.
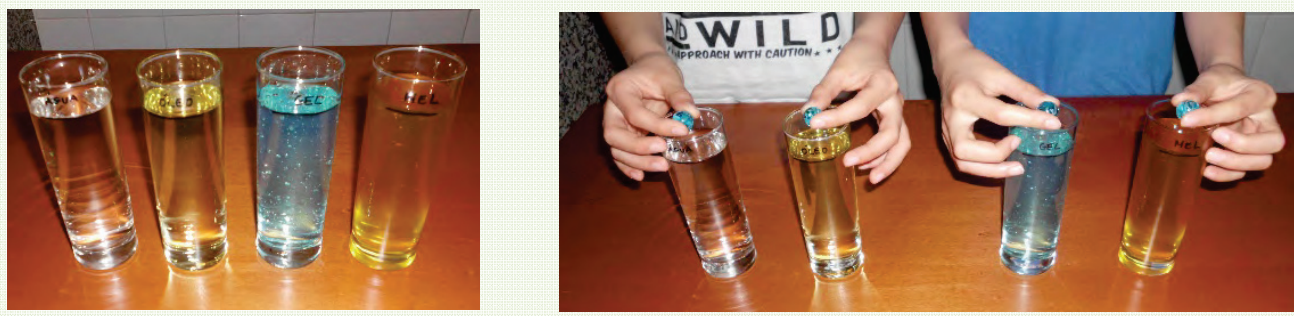

7. Recuperar os berlindes com o auxílio da colher. Se houver dúvidas na ordem de chegada, corrigir o nível dos líquidos enchendo novamente até à marca e repetir o processo somente com os líquidos em dúvida.

8. Para efectuar a experiência de um modo mais quantitativo, verificar com um copo de cada vez, qual o tempo que demora até o berlinde chegar ao fundo do copo, utilizando o cronómetro. Registar as observações no quadro abaixo.

\section{Observações:}

\begin{tabular}{|c|c|c|c|c|}
\hline Líquido & água & mel & óleo & gel de banho \\
\hline $\begin{array}{l}\text { Tempo que o } \\
\text { berlinde demorou a } \\
\text { chegar ao fundo do } \\
\text { copo (segundos) }\end{array}$ & & & & \\
\hline
\end{tabular}

9. Colocar o copo com mel no frigorífico durante uma hora.

10. Verificar com o mel arrefecido qual o tempo que um berlinde demora a chegar ao fundo.

11. Recuperar o berlinde com o auxílio da colher e corrigir o volume de líquido se necessário. 
12. Deixar o copo atingir a temperatura ambiente e, seguidamente, colocá-lo dentro de um recipiente com água bem quente durante uma hora.

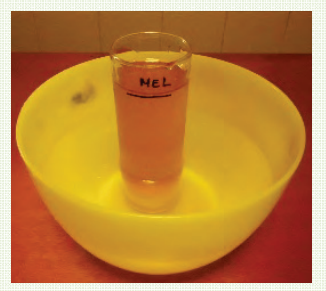

13. Verificar novamente o tempo que o mesmo berlinde demora a chegar ao fundo. Registar estas observações no quadro abaixo.

Observações:

\begin{tabular}{l|l|l|}
\hline Tempo que o & Melfrio \\
Terlinde demorou a \\
chegar ao fundo do \\
copo (segundos)
\end{tabular}

14. Lavar os copos e encher três deles com gel de banho até à marca.

15. Com os três berlindes de tamanhos diferentes verificar o tempo que cada um demora a chegar ao fundo do copo, efectuando de novo a experiência da largada dos berlindes. Registar os tempos observados no quadro abaixo.
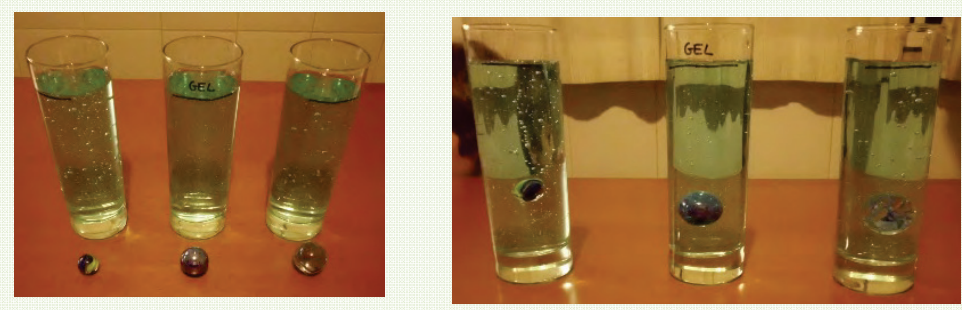

Observações:

Berlinde
Tempo que o
berlinde demorou a
chegar ao fundo do
copo (segundos)




\section{Explicação:}

A viscosidade é uma propriedade das substâncias que mede a resistência ao escoamento, ou seja uma substância mais viscosa move-se mais lentamente do que uma menos viscosa, que por seu lado se diz mais fluida. Nesta actividade testámos a viscosidade de vários líquidos de uso corrente. Alguns líquidos como a água têm baixa viscosidade, se os entornar-mos eles escoam rapidamente. Outros, como o mel, têm viscosidade elevada e demoram mais tempo a mexer-se. Quando deixamos cair um berlinde dentro de cada uma das amostras, este movimentou-se mais rápido nos líquidos menos viscosos e mais devagar nos mais viscosos, por isso os tempos foram menores para a água e maiores para o mel. A viscosidade depende de vários factores como a

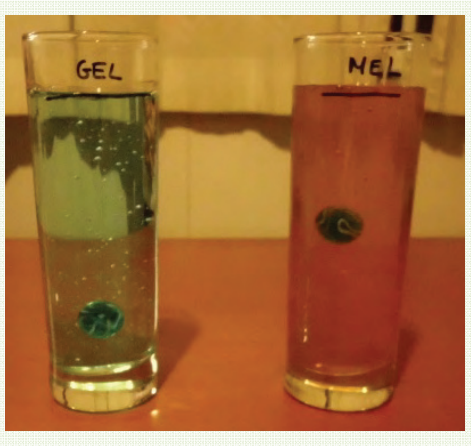
natureza ou composição da substância, a temperatura e a pressão a que estão sujeitas. Neste caso testámos o que acontecia com a temperatura - ao arrefecermos o mel o berlinde ficou mais lento e ao aquecermos ficou mais rápido, ou seja a viscosidade diminuiu com o aumento de temperatura. Isto acontece porque quando aumentamos a temperatura de uma substância, as particulas que a constituem movimentam-se mais rapido, ou seja, a substância fica mais fluida, de modo semelhante ao que acontece nas transições entre os estados físicos, sólido/líquido/gasoso. O berlinde cai mais rápido no mel quente. Por último quando testámos berlindes de diferentes dimensões (atenção que o diâmetro do berlinde maior deve ser inferior a metade do diâmetro do copo, para que as paredes não interfiram) obtivemos tempos diferentes. A velocidade com que o berlinde cai vai depender da sua densidade, da sua dimensão, e da viscosidade do líquido. Sendo a viscosidade idêntica, porque é a mesma substância, e assumindo que os berlindes são feitos do mesmo material, a sua velocidade vai depender do seu tamanho, quanto maior, mais veloz.

\section{Bibliografia}

[1] Adaptado de Science Buddies Staff (22 Janeiro de 2015), "Race Your Marbles to Discover a Liquid's Viscosity", http://www.sciencebuddies.org/science-fair-projects/project_ideas/Chem_p055.shtml (acedido a 27-04-2015) 